\title{
Photopolymerized Thermosensitive Poly(HPMAlactate)-PEG-Based Hydrogels: Effect of Network Design on Mechanical Properties, Degradation, and Release Behavior
}

\author{
Roberta Censi, ${ }^{\dagger, \ddagger}$ Tina Vermonden, ${ }^{\dagger}$ Hendrik Deschout, ${ }^{\S}$ Kevin Braeckmans, ${ }^{\S}$ \\ Piera di Martino, ${ }^{\ddagger}$ Stefaan C. De Smedt, ${ }^{\S}$ Cornelus F. van Nostrum, ${ }^{\dagger}$ and \\ Wim E. Hennink ${ }^{*, \dagger}$

\begin{abstract}
Department of Pharmaceutics, Utrecht Institute for Pharmaceutical Sciences (UIPS), Utrecht University, P.O. Box 80082, 3508 TB Utrecht, The Netherlands, Department of Chemical Sciences, Camerino University, via S, Agostino 1, 62032, Camerino (MC), Italy, and Laboratory of General Biochemistry and Physical Chemistry, Department of Pharmaceutics, Ghent University, Harelbekestraat 72, B-9000, Ghent, Belgium
\end{abstract}

Received May 11, 2010; Revised Manuscript Received June 18, 2010

\begin{abstract}
Photopolymerized thermosensitive A-B-A triblock copolymer hydrogels composed of poly( $N$-(2-hydroxypropyl)methacrylamide lactate) A-blocks, partly derivatized with methacrylate groups to different extents $(10,20$, and $30 \%$ ) and hydrophilic poly(ethylene glycol) B-blocks of different molecular weights (4, 10, and $20 \mathrm{kDa}$ ) were synthesized. The aim of the present study was to correlate the polymer architecture with the hydrogel properties, particularly rheological, swelling, degradation properties and release behavior. It was found that an increasing methacrylation extent and a decreasing PEG molecular weight resulted in increasing gel strength and cross-link density, which tailored the degradation profiles from 25 to more than 300 days. Polymers having small PEG blocks showed a remarkable phase separation into polymer- and water-rich domains, as demonstrated by confocal microscopy. Depending on the hydrophobic domain density, the loaded protein resides in the hydrophilic pores or is partitioned into hydrophilic and hydrophobic domains, and its release from these compartments is tailored by the extent of methacrylation and by PEG length, respectively. As the mechanical properties, degradation, and release profiles can be fully controlled by polymer design and concentration, these hydrogels are suitable for controlled protein release.
\end{abstract}

\section{Introduction}

The design of a controlled drug delivery system is usually based on the drug's physicochemical and pharmacokinetic properties and aimed to prevent drug's rapid clearance, inducing a desired pharmacological response over a prolonged period of time and to obviate potentially harmful plasma peak concentrations, normally occurring upon bolus injection. ${ }^{1-3}$ Despite the encouraging progress in the field of controlled drug delivery over the past decades, some important clinical needs are still unmet. Conventional delivery systems suffer from the limitation of minimal synchronization between the required time for therapeutically effective drug plasma concentrations and the actual drug release profile exhibited by the dosage form. These considerations have upraised the importance of drug delivery systems fulfilling the drug's therapeutic requirements and have shifted the focus of scientists toward the design of idealized drug formulations, wherein the required amount of active agent is made available at the desired time and site of action in the body. ${ }^{4}$

Hydrogels are three-dimensional networks of physically and chemically cross-linked polymers that imbibe large amounts of water, mimicking tissues and allowing encapsulation and release of biomolecules in a physiologically relevant setting and they

* To whom correspondence should be addressed. Tel.: +31 302536964 . Fax: +31 30251 7839. E-mail: w.e.hennink@uu.nl.

${ }^{\dagger}$ Utrecht University.

*amerino University.

$\S$ Ghent University. have emerged as promising candidates in this respect. ${ }^{5-7}$ Besides their ability to circumvent some of the complexities associated with the release of biotherapeutics from hydrophobic polymers (e.g., degradable copolymers of lactic and glycolic acid) such as protein denaturation ${ }^{8,9}$ and immunogenic response toward the entrapped protein, ${ }^{10}$ they exhibit the capability to modify the pharmacological performance of various classes of drugs by precise modulation of their release in a sustained and tailorable fashion. ${ }^{5}$ Amphiphilic block copolymers are a particular class of suitable hydrogel building blocks because of their ability to self-assemble, as well as flexibility of block copolymer chemistry, which allows the realization of welldefined molecular architectures of hydrogel networks, thereby tailoring their macroscopic properties and drug release behavior. Moreover, another crucial functionality of synthetic block copolymer-based hydrogels is their biodegradability.

Hydrogel networks composed of hydrophilic polymers such as poly(ethylene glycol) (PEG) $)^{11,12}$ or poly(vinyl alcohol) $(\mathrm{PVA})^{13}$ are particularly suitable to carry out the above functions, as these materials possess physicochemical characteristics that closely mimic those of natural tissues. This characteristic is well suited for the design of "smart" biomaterials with tunable bioresponsive functions. Degradation and drug release kinetics in a given biological environment can be readily controlled by the polymer molecular weight and functionality, as well as the overall polymer content. ${ }^{14-18}$

In our previous work, we have described a class of synthetic biodegradable polymers, exhibiting lower critical solution 
temperature (LCST) behavior in an aqueous solution that potentially can be used to design injectable in situ forming hydrogels. ${ }^{19,20}$ The aforementioned polymer has an A-B-A architecture consisting of thermosensitive poly $(N$-(2-hydroxypropyl)methacrylamide lactate) (p(HPMAm-lac) A-blocks that are partly modified with methacrylate moieties, to allow chemical cross-linking using photopolymerization, and a B-block of poly(ethylene glycol) (PEG). ${ }^{21,22}$ The p(HPMAm-lac) Ablocks exhibit thermosensitive behavior, having a cloud point (CP) that can be tuned by the average length of the lactate side chains. ${ }^{21}$ This property allows the design of a polymer that selfassembles in aqueous solution upon injection in vivo, because its $\mathrm{CP}$ is lower than $37{ }^{\circ} \mathrm{C} . .^{23}$ This body temperature induced formation of a macroscopic gel at the site of injection is particularly beneficial for the patient, implying minimally invasive administration, enhanced shape adaptation, and cost reduction compared to surgical implantation. ${ }^{24,25}$ Moreover, the use of thermosensitive polymer gels permits the encapsulation of active compounds during the network formation, overcoming complexities and limitations associated with postloading techniques.

Despite the numerous advantages of physically cross-linked hydrogels, their rapid swelling and subsequent dissolution in physiological environment limits their applicability as controlled delivery systems. Therefore, chemical cross-linking methods are additionally used to stabilize the hydrogel structure. ${ }^{26-29}$ To this end, in our approach, UV photopolymerization is applied upon association of the thermosensitive blocks above their $\mathrm{CP}$ and, as a result, the structural stability of the hydrogel is remarkably enhanced. ${ }^{30-34}$ Photopolymerization is a widely utilized technique to realize spatially and temporally controlled chemical cross-linking of hydrogels suitable for drug delivery and tissue engineering. Potentially, it can be implemented by means of laparoscopy or transdermal illumination in case of subcutaneously injected depot systems. ${ }^{35,36}$

Besides thermosensitivity, degradability is another advantageous characteristic of our hydrogel system, which is ensured by the presence of hydrolytically sensitive ester bonds in the lactate side chains as well as in the ester bonds connecting PEG and the thermo-blocks. ${ }^{37}$ Under physiological conditions, hydrolytical degradation of the hydrogel eventually results in lowtoxicity degradation products, that is, PEG, p(HPMAm), polymethacrylic, and lactic acid, which can be either metabolized or eliminated through renal filtration.

We have shown that the described thermosensitive polymerbased hydrogel is a suitable controlled delivery system for proteins, being the release mechanism mediated by Fickian diffusion of the biomolecule through the gel network. ${ }^{30}$ It was further shown that the diffusivity of entrapped proteins could be tailored by the polymer concentration and depended on the protein molecular weight. Additionally, the preservation of the structural and functional integrity of the protein was demonstrated. ${ }^{30}$

The present study aimed to explore the tailorability of the described hydrogel by the molecular structure of the polymer, varying PEG's molecular weight (MW) and degree of methacrylation (DM), and investigates how these properties affect the cross-link density. The flexibility of the polymer chemistry indeed offers the opportunity to create a variety of hydrogels with well-defined physicochemical properties and reproducible and modular release profiles. ${ }^{16,18,38}$

\section{Materials and Methods}

Materials. Unless indicated otherwise, the chemicals were obtained from Sigma-Aldrich and were used as received. L-Lactide was obtained from Purac Biochem BV (Gorinchem, The Netherlands), and Irgacure 2959 was obtained from Ciba Specialty Chemicals Inc. 4,4'-Azobis(4cyanopentanoic acid) was obtained from Fluka Chemie AG (Buchs, Switzerland). HPMAm-monolactate and HPMAm-dilactate were synthesized according to a previously reported method. ${ }^{21}$ The synthesis of triblock copolymers with PEGs as middle block and polyHPMAmlactate as outer blocks was described previously ${ }^{22,30,31}$ and applied in this study for the preparation of triblock copolymers having fixed p(HPMAm-lac) A-blocks of $22 \mathrm{kDa}$, derivatized with $20 \%$ of methacrylate groups and PEGs of varying molecular weight (4, 10, 20, 40 $\mathrm{kDa}$ B-blocks and polymers having a PEG $10 \mathrm{kDa}$ B-block, p(HPMAm-lac) $22 \mathrm{kDa}$ A-blocks, modified with 10, 20, and $30 \%$ of methacrylate moieties. Bovine serum albumin (BSA), fluorescein isothiocyanate bovine serum albumin (FITC-BSA), and Nile Red (NR) were purchased from Sigma Aldrich.

${ }^{1}$ H NMR Spectroscopy. ${ }^{1} \mathrm{H}$ NMR (300 MHz) spectra were recorded on a Gemini $300 \mathrm{MHz}$ spectrometer (Varian Associates Inc., NMR Instruments, Palo Alto, CA) using DMSO- $d_{6}$ as a solvent. Chemical shifts were referred to the solvent peak ( $\delta=2.49 \mathrm{ppm}$ for DMSO- $d_{6}$ ).

Gel Permeation Chromatography. The molecular weights of the polymers were determined by GPC using a Plgel $5 \mu \mathrm{m}$ MIXED-D column (Polymer Laboratories) with a column temperature of $40{ }^{\circ} \mathrm{C}$. DMF containing $10 \mathrm{mM} \mathrm{LiCl}$ was used as eluent with an elution rate of $0.7 \mathrm{~mL} / \mathrm{min}$, and the sample concentration was $5 \mathrm{mg} / \mathrm{mL}$ in the same eluent. Poly(ethylene glycols) with defined molecular weights were used as calibration standards. ${ }^{21}$

Determination of the Cloud Point. The cloud point (CP) of the polymers was measured with static light scattering using a Horiba Fluorolog fluorometer $\left(650 \mathrm{~nm}, 90^{\circ}\right.$ angle). The polymers were dissolved at a concentration of $3 \mathrm{mg} / \mathrm{mL}$ in ammonium acetate buffer

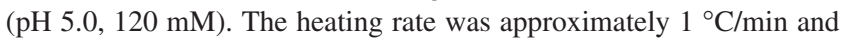
every $0.2{ }^{\circ} \mathrm{C}$ the scattering intensity was measured at $90^{\circ}$ angle. The $\mathrm{CP}$ is defined as the onset of increasing scattering intensity. ${ }^{37}$

Synthesis of Methacrylated Triblock Copolymers. Thermosensitive triblock copolymers consisting of PEG 4, 10, 20, and $40 \mathrm{kDa}$ as hydrophilic block and pHPMAm $_{\text {lac }}$ as thermosensitive outer blocks with a HPMAm-monolactate/HPMAm-dilactate ratio of 50/50 were synthesized by free radical polymerization using (PEG-ABCPA) $n$ macroinitiators according to a method described earlier. ${ }^{22}$ The $\mathrm{OH}$ side groups of $\mathrm{p}(\mathrm{HPMAm}-\mathrm{lac})$ were partially methacrylated using the following procedure. The triblock copolymers $(28.5 \mathrm{mmol})$ were dissolved in dry THF under a $\mathrm{N}_{2}$ atmosphere. Dimethylaminopyridine (DMAP; 0.15, 0.30 , and $0.45 \mathrm{mmol}$, for 10,20 , and $30 \%$ methacrylation, respectively) and triethylamine (TEA; 3.8, 7.6, and $11.4 \mathrm{mmol}$ for 10, 20, and 30\% methacrylation, respectively) were added at $0{ }^{\circ} \mathrm{C}$. Methacrylic anhydride (MA; 3.8, 7.6, and $11.4 \mathrm{mmol}$ for 10,20 , and $30 \%$ methacrylation, respectively) at a 1:1 molar ratio with TEA was added as the last component. The reaction mixture was subsequently stirred for $24 \mathrm{~h}$ at room temperature. Afterward, the polymers were diluted with water, dialyzed (membrane with a cutoff of 12-14 kDa) against water for 2 days and isolated by freeze-drying. The synthesized polymers were characterized by ${ }^{1} \mathrm{H}$ NMR (DMSO- $\left.d_{6}\right): \delta 7.35(1 \mathrm{H}, \mathrm{b}, \mathrm{N} H), 6.15$ and $5.80\left(2 \mathrm{H}, \mathrm{d}, \mathrm{C}=\mathrm{CH}_{2}\right), 5.4(1 \mathrm{H}, \mathrm{d}, \mathrm{CH}-\mathrm{OH}), 4.95\left(\mathrm{~d}, \mathrm{CO}-\mathrm{CH}\left(\mathrm{CH}_{3}\right)-\mathrm{O}\right)$, $4.1\left(1 \mathrm{H}, \mathrm{d}, \mathrm{CO}-\mathrm{CH}\left(\mathrm{CH}_{3}\right)-\mathrm{OH}\right), 3.60\left(904 \mathrm{H}, \mathrm{s}, \mathrm{OCH}_{2} \mathrm{CH}_{2}\right.$ (PEGprotons)), $3.4\left(2 \mathrm{H}, \mathrm{s}, \mathrm{NHCH}_{2}\right.$ ), 2.2-0.6 (main chain protons and $\mathrm{CH}_{3}$ of lactate groups). The degree of methacrylation (DM), defined as the percentage of $\mathrm{OH}$ groups derivatized with methacrylate moieties, was calculated from the ratio of the average intensity of the peaks at 6.15 and 5.80 and intensity of the peak at $5.4 \mathrm{ppm}$ as follows: $\left(\left(I_{6.15}+I_{5.8}\right) /\right.$ $2) /\left(\left(I_{6.15}+I_{5.8}\right) / 2+I_{5.4}\right) \times 100 \% .^{31}$

Preparation of Placebo and Protein-Loaded Hydrogels. Hydrogels of $100 \mathrm{mg}$ were prepared in cylindrically shaped glass vials (diameter of $5 \mathrm{~mm}$ ) as follows. Triblock copolymers (20 and $35 \mathrm{mg}$ ) were dissolved in 60 and $65 \mu \mathrm{L}$ of PBS buffer, $\mathrm{pH} 7.4(8.2 \mathrm{~g} / \mathrm{L} \mathrm{NaCl} ; 3.1$ 
$\mathrm{g} / \mathrm{L} \mathrm{NaH} \mathrm{PO}_{4} 12 \mathrm{H}_{2} \mathrm{O} ; 0.3 \mathrm{~g} / \mathrm{L} \mathrm{NaH}_{2} \mathrm{PO}_{4}$, supplemented with $0.02 \%$ $\mathrm{NaN}_{3}$ ), respectively. Next, $20 \mu \mathrm{L}$ of an Irgacure 2959 solution $(2.5$ $\mathrm{mg} / \mathrm{mL}$ ) was added. The final polymer concentrations were 20 and 35 wt $\%$, while the Irgacure concentration was $0.05 \mathrm{wt} \%$. The samples were then incubated at $4{ }^{\circ} \mathrm{C}$ for $2 \mathrm{~h}$ to fully dissolve the polymers and subsequently heated to $40{ }^{\circ} \mathrm{C}$ before photopolymerization. A BluePoint lamp 4 (350-450 nm, Honle UV technology, light intensity of 450 $\mathrm{mW} / \mathrm{cm}^{2}$ ) was used over a period of $5 \mathrm{~min}$ for the photopolymerization of the hydrogels. A glass filter between the sample and the light source was used to cut off light wavelength below $300 \mathrm{~nm}$ and prevent protein degradation. BSA- or FITC-BSA-loaded hydrogels were prepared according to a slightly different procedure. The triblock copolymers, 20 and $35 \mathrm{mg}$, were dissolved in 40 and $25 \mu \mathrm{L}$ of PBS solution (composition see above) for 20 and $35 \mathrm{wt} \%$ polymer hydrogels, respectively. Upon dissolution of the polymer at $4{ }^{\circ} \mathrm{C}, 20 \mu \mathrm{L}$ of an Irgacure solution in PBS $(2.5 \mathrm{mg} / \mathrm{mL})$ and $20 \mu \mathrm{L}$ of a BSA $(100 \mathrm{mg} /$ $\mathrm{mL})$ or FITC-BSA $(10 \mathrm{mg} / \mathrm{mL})$ solution in the same buffer was added to yield a hydrogel containing $2 \mathrm{wt} \%$ protein or $0.2 \mathrm{wt} \%$ fluorescently labeled protein, $0.05 \mathrm{wt} \%$ Irgacure, and 20 or $35 \mathrm{wt} \%$ polymer. The hydrogels were first physically (thermogelling) and subsequently chemically photo-cross-linked as described above.

Swelling and Degradation Studies. Hydrogels were prepared in 1 $\mathrm{mL}$ glass vials, and the exact weight of the gel was measured $\left(W_{0}\right)$. The vials were incubated at $37{ }^{\circ} \mathrm{C}$ and $0.9 \mathrm{~mL}$ of PBS buffer, $\mathrm{pH} 7.4$, containing $0.02 \% \mathrm{NaN}_{3}$ was added. At regular intervals, the incubation buffer was removed and the weight of the gel was measured $\left(W_{\mathrm{t}}\right)$ to calculate the swelling ratio $\left(\mathrm{SR}=W_{\mathrm{t}} / W_{0}\right)$. Next, $0.9 \mathrm{~mL}$ buffer was added and the samples were further incubated at $37{ }^{\circ} \mathrm{C} .{ }^{30}$

Rheological Characterization. The rheological analysis of the photopolymerized hydrogels was performed on an AR-G2 rheometer (TA-Instruments) equipped with UHP device connected to a BluePoint 4 mercury lamp (Honle UV technology, range 230-500 nm, intensity of $50 \mathrm{~mW} / \mathrm{cm}^{2}$ ). Gels were studied at $37{ }^{\circ} \mathrm{C}$ using a plate-plate geometry. A $0.1 \%$ strain was applied. The physically cross-linked gels were photopolymerized in situ while measured. ${ }^{30}$

Release Studies. In vitro release of BSA from the photopolymerized gels was studied in $1 \mathrm{~mL}$ cylindrical glass vials. The hydrogels (100 $\mathrm{mg}$ ), placed on the bottom of the vial, were exposed to $0.9 \mathrm{~mL}$ of PBS buffer, pH 7.4 (8.2 g/L NaCl; $3.1 \mathrm{~g} / \mathrm{L} \mathrm{NaH} \mathrm{NaO}_{4} 12 \mathrm{H}_{2} \mathrm{O} ; 0.3 \mathrm{~g} / \mathrm{L}$ $\mathrm{NaH}_{2} \mathrm{PO}_{4}$, supplemented with $0.02 \%$ to prevent bacterial growth). Only the top surface of the hydrogels was exposed to the incubation medium. The vials were incubated in a shaking water bath of $37^{\circ} \mathrm{C}$. Samples of $150 \mu \mathrm{L}$ of the acceptor medium were taken in time and replaced by an equal volume of fresh buffer. The concentration of BSA was determined using an Acquity UPLC with a BEH C18 $1.7 \mu \mathrm{m}, 2.1-50 \mathrm{~mm}$ column. A mobile phase gradient from $100 \%$ of eluent A $\left(95 / 5 / 0.1 \% \mathrm{H}_{2} \mathrm{O} /\right.$ acetonitrile/trifluoroacetic acid) to $100 \%$ of B (100/0.1\% acetonitrile/ trifluoroacetic acid) in a $10 \mathrm{~min}$ run time was used. The injection volumes of the samples were $5 \mu \mathrm{L}$, the flow rate was $0.250 \mathrm{~mL} / \mathrm{min}$, and detection was done at $280 \mathrm{~nm}$. For calibration, three solutions of BSA freshly dissolved at concentrations of $0.1,0.5$, and $1 \mathrm{mg} / \mathrm{mL}$ were prepared, and the injected volumes varied from 0.5 to $7.5 \mu \mathrm{L}$.

Confocal Laser Scanning Microscopy (CLSM). FITC-BSA loaded hydrogels were prepared as described in the previous section. Prior to photopolymerization, the hydrogels were heated at $37{ }^{\circ} \mathrm{C}$ and a trace amount of NR was added to the hydrogel. The hydrogels were incubated at $37{ }^{\circ} \mathrm{C}$ for $2 \mathrm{~h}$ to allow partitioning of NR into the hydrophobic domains of the gels. Subsequently, the hydrogels were placed on a microscope slide and covered with a sealed coverslip. The hydrogel was photopolymerized and confocal images were obtained using a Zeiss/ Biorad Radiance 2100MP multiphoton microscope (Jena, Germany) equipped with Argon $(488 \mathrm{~nm})$ and $\mathrm{HeNe}(543$ and $633 \mathrm{~nm})$ lasers and a $100 \times$ water immersion objective lens. Fluorescence detection was performed with standard filter cubes settings for the detection of the FITC and NR labels. The hydrogels were maintained at a temperature of $37{ }^{\circ} \mathrm{C}$ using a Solent Scientific climate chamber (Segensworth, U.K.).
Scheme 1. Chemical Structure of A-B-A Triblock Copolymers Composed of Methacrylated p(HPMAm-lac) A-Blocks and PEG B-Block

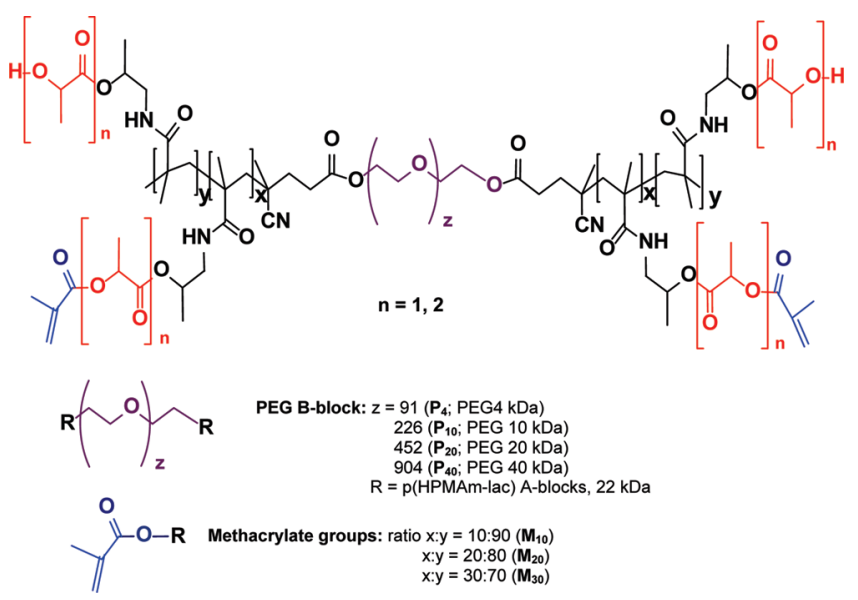

Table 1. Characteristics of A-B-A Triblock Copolymers Composed of (Methacrylated) p(HPMAm-lac) A-Blocks and PEG B-Block

\begin{tabular}{lccccc}
\hline name & $\begin{array}{c}\mathrm{PEG} \\
\mathrm{MW} \\
(\mathrm{kDa})\end{array}$ & $\begin{array}{c}\mathrm{DM} \\
(\%)^{a}\end{array}$ & $\begin{array}{c}M_{\mathrm{n}} \text { of } \\
\begin{array}{c}\text { blocks } \\
(\mathrm{kDa})^{a}\end{array}\end{array}$ & $\begin{array}{c}M_{\mathrm{n}} \text { of } \\
\text { A-B-A } \\
\text { triblock } \\
(\mathrm{kDa}) / \mathrm{PDI}^{b}\end{array}$ & $\begin{array}{r}\mathrm{CP}^{c} \\
\left({ }^{\circ} \mathrm{C}\right)\end{array}$ \\
\hline $\mathrm{M}_{0} \mathrm{P}_{10}$ & 10 & 0 & 23.5 & $38.1 / 1.9$ & 29 \\
$\mathrm{M}_{10} \mathrm{P}_{10}$ & 10 & 10 & 22 & $39.2 / 2.0$ & 21 \\
$\mathrm{M}_{20} \mathrm{P}_{10}$ & 10 & 20 & 23 & $39.7 / 1.8$ & 14 \\
$\mathrm{M}_{30} \mathrm{P}_{10}$ & 10 & 30 & 21.5 & $40.1 / 1.8$ & 8 \\
$\mathrm{M}_{20} \mathrm{P}_{4}$ & 4 & 20 & 23.5 & $27.1 / 2.1$ & 15 \\
$\mathrm{M}_{20} \mathrm{P}_{20}$ & 20 & 20 & 22.5 & $47.5 / 2.0$ & 14 \\
$\mathrm{M}_{20} \mathrm{P}_{40}$ & 40 & 20 & 23 & $53.2 / 1.9$ & 16 \\
\hline
\end{tabular}

${ }^{a}$ Determined by ${ }^{1} \mathrm{H}$ NMR. ${ }^{b}$ Determined by GPC. ${ }^{c}$ Determined by SLS.

\section{Results and Discussion}

Polymer Characteristics. A series of A-B-A triblock copolymers consisting of pHPMAm-lac A-blocks of approximately $22 \mathrm{kDa}$, PEG molecular weight (MW) of $10 \mathrm{kDa}$ (B block), and with a varying methacrylation extent (DM) of 10, 20, and $30 \%$ were synthesized. Also triblock copolymers with different PEG B-block molecular weight of 4, 10, and $20 \mathrm{kDa}$ were prepared, while keeping the methacrylation extent and the A-blocks molecular weight constant $(20 \%$ and $22 \mathrm{kDa}$, respectively). The polymers are abbreviated as $\mathrm{M}_{x} \mathrm{P}_{y}$, where $\mathrm{M}_{x}$ indicates the degree of methacrylation (i.e., $\mathrm{M}_{10}$ for a $\mathrm{DM}$ of $10 \%$ ) and $\mathrm{P}_{y}$ the PEG molecular weight (i.e., $\mathrm{P}_{10}$ for PEG 10 $\mathrm{kDa}$ ). Scheme 1 shows the chemical structure and Table 1 the characteristics of the synthesized polymers.

For all the synthesized polymers, the copolymer composition (DP1/DP2 ratio), as determined by ${ }^{1} \mathrm{H}$ NMR, corresponded to the feed ratio of 50:50. The polymer $\mathrm{M}_{0} \mathrm{P}_{10}$ (Table 1) had a $\mathrm{CP}$ of $29{ }^{\circ} \mathrm{C}$, which dropped to 21,14 , and $8{ }^{\circ} \mathrm{C}$ upon $10\left(\mathrm{M}_{10} \mathrm{P}_{10}\right)$, $20\left(\mathrm{M}_{20} \mathrm{P}_{10}\right)$, and $30 \%\left(\mathrm{M}_{30} \mathrm{P}_{10}\right)$ methacrylation, respectively. As reported previously, this decrease in $\mathrm{CP}$ is due to an increased polymer hydrophobicity as a result of the introduction of methacrylate groups on the lactate side chains. ${ }^{30,31}$ The variation of PEG molecular weight had no influence on the cloud point of the triblock copolymers $\mathrm{M}_{20} \mathrm{P}_{4}, \mathrm{M}_{20} \mathrm{P}_{10}, \mathrm{M}_{20} \mathrm{P}_{20}$, and $\mathrm{M}_{20} \mathrm{P}_{40}$ (Table 1). The molecular weights of the polymers, calculated according to ${ }^{1} \mathrm{H}$ NMR and measured by GPC are listed in Table 1. It appears that the values based on GPC analysis exceed those based on ${ }^{1} \mathrm{H}$ NMR analysis. It was shown earlier that this discrepancy can be ascribed on the use of PEG homopolymers as GPC standards that display larger hydrodynamic volumes than the triblock copolymers. ${ }^{22,39}$ All the synthesized polymers 
Table 2. Methacrylate Conversion of Hydrogels Consisting of A-B-A Triblock Copolymers (Table 1)

\begin{tabular}{lcc}
\hline name & polymer content (wt\%) & methacrylate conversion (\%) \\
\hline $\mathrm{M}_{10} \mathrm{P}_{10}$ & 20 & $94 \pm 3$ \\
$\mathrm{M}_{20} \mathrm{P}_{10}$ & 35 & $79 \pm 5$ \\
& 20 & $93 \pm 7$ \\
$\mathrm{M}_{30} \mathrm{P}_{10}$ & 35 & $71 \pm 6$ \\
$\mathrm{M}_{20} \mathrm{P}_{4}$ & 20 & $94 \pm 1$ \\
& 35 & $76 \pm 3$ \\
$\mathrm{M}_{20} \mathrm{P}_{20}$ & 20 & $98 \pm 2$ \\
& 35 & $75 \pm 5$ \\
& 20 & $94 \pm 4$ \\
\hline
\end{tabular}

had a yield of polymerization of $72 \pm 3 \%$ and the conversion of the methacrylic anhydride during the methacrylation reaction was $45 \pm 5 \%$, in agreement with previous results. ${ }^{30,31}$

Hydrogels, with initial solid contents of 20 and 35\% were prepared from the different triblock copolymers listed in Table 1 .

Mechanical Characterization of Hydrogels. The chemical cross-linking efficiency after UV-photopolymerization was studied by determination of the unreacted methacrylic groups, upon degradation of the gels (Table 2), as described earlier. ${ }^{30}$ It was found that, regardless of the PEG molecular weight and the extent of methacrylation, the methacrylate conversion was approximately 75 and $95 \%$ for hydrogels of 35 and $20 \%$ polymer concentrations, respectively.

These data are in line with previous observations, where it was reasoned that the decreased methacrylate conversion at increased polymer concentration can be attributed to the higher cloudiness of polymer richer hydrogels, leading to diminished capability of the light to penetrate into the sample. ${ }^{30}$

The mechanical characterization of the hydrogels was performed by rheological measurements. In previous papers, we demonstrated that physical hydrogels are formed at temperatures below $37{ }^{\circ} \mathrm{C}^{22}$ and that the UV photopolymerization induced a remarkable and immediate stabilization of the hydrophobic domains by chemical cross-linking of the methacrylate groups on the lactate side chains. ${ }^{30}$

In Figure 1, the influence of methacrylation extent on the rheological properties of 20 and 35 wt \% polymer hydrogels is shown. As expected, the storage moduli clearly indicate that for both polymer concentrations the cross-linking density increases with increasing methacrylation extent, indicating the formation of a tighter and more rigid network when the polymer is derivatized with more methacrylate moieties. For all the hydrogel formulations studied, $\tan \delta\left(G^{\prime \prime} / G^{\prime}\right)$ was found between 0.1 and 0.3 , demonstrating that almost fully elastic gels were formed.

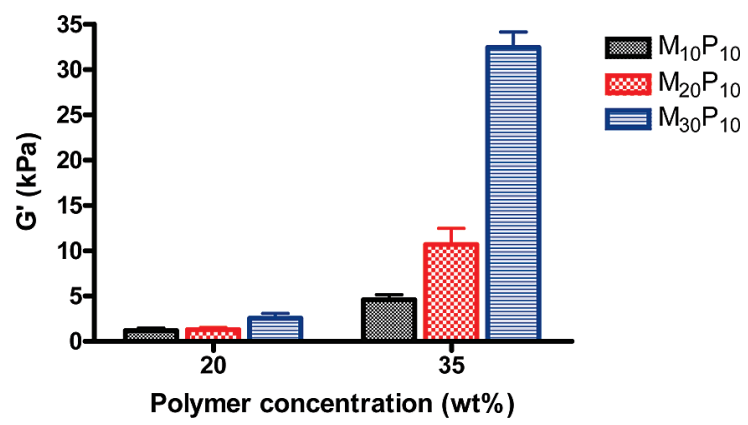

Figure 1. Effect of methacrylation extent of $M_{10} P_{10}, M_{20} P_{10}$, and $M_{30} P_{10}$ (Table 1) on storage moduli $\left(G^{\prime}\right)$ of photopolymerized hydrogels for 20 and 35 wt \% of polymer concentration. Data are shown as mean \pm standard deviation; $n=3$.

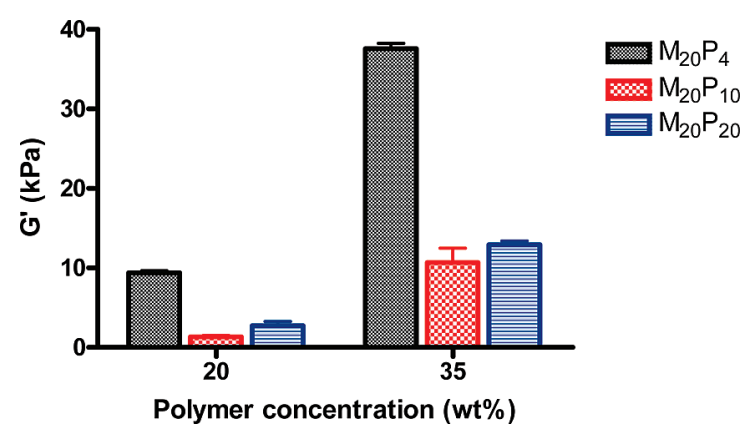

Figure 2. Effect of $P E G$ middle block molecular weight of $M_{20} P_{4}$, $M_{20} P_{10}$, and $M_{20} P_{20}$ (Table 1) on storage moduli $\left(G^{\prime}\right)$ of photopolymerized hydrogels for 20 and $35 \mathrm{wt} \%$ of polymer concentration. Data are shown as mean \pm standard deviation; $n=3$.

Figure 2 shows the effect of PEG middle block molecular weight on the mechanical properties of hydrogels. In line with expectations, the hydrogel with the highest polymer concentration exhibited the highest $G^{\prime}(9.4 \pm 0.3 \mathrm{kPa}$ and $37.6 \pm 0.6$ $\mathrm{kPa}$, for $20 \mathrm{M}_{20} \mathrm{P}_{4}$ and $35 \mathrm{M}_{20} \mathrm{P}_{4}$ wt $\%$, respectively). However, $\mathrm{M}_{20} \mathrm{P}_{20}$ hydrogels showed higher storage moduli as compared to $\mathrm{M}_{20} \mathrm{P}_{10}$ analogues. This evidence did not confirm the trend observed in nonphotopolymerized hydrogels, where polymers of shorter PEG length yielded a stronger hydrogel. ${ }^{40}$ Hydrogels having shorter PEG length are expected to have higher $G^{\prime}$ for two reasons. First, because at equal weight percentage of the polymer, the molar concentration of $\mathrm{M}_{20} \mathrm{P}_{4}$, having the smallest molecular weight, is higher as compared to the molar concentration of $\mathrm{M}_{20} \mathrm{P}_{10}$ and $\mathrm{M}_{20} \mathrm{P}_{20}$. Second, because $\mathrm{M}_{20} \mathrm{P}_{4}$ hydrogels, characterized by a remarkable hydrophobicity above the $\mathrm{CP}$, expelled some water upon gel formation, resulting in a higher polymer concentration. This was not observed for $\mathrm{M}_{20} \mathrm{P}_{10}$ and $\mathrm{M}_{20} \mathrm{P}_{20}$ hydrogels, where the hydrophobicity of the p(HPMAmlac) chains above the $\mathrm{CP}$ is well balanced by the hydrophilicity of the PEG middle block. The higher molar concentration of $\mathrm{M}_{20} \mathrm{P}_{4}$ gels along with its marked hydrophobicity might also lead to a different number of self-assembling thermosensitive chains associated in each hydrophobic domain.

The observation that the $\mathrm{M}_{20} \mathrm{P}_{20}$ hydrogels had higher $G^{\prime}$ as compared to $\mathrm{M}_{20} \mathrm{P}_{10}$ for both hydrogel concentration (Figure 2) is most likely due to the larger contribution of the entanglements of the PEG $20 \mathrm{kDa}$ chains to the network strength. The evidence that PEG $20 \mathrm{kDa}$ chain entanglements play a crucial role in the $\mathrm{M}_{20} \mathrm{P}_{20}$ network properties is reflected by the substantial higher viscosity of the $\mathrm{M}_{20} \mathrm{P}_{20}$ solution compared to $\mathrm{M}_{20} \mathrm{P}_{10}$ and $\mathrm{M}_{20} \mathrm{P}_{4}$ below the CP (data not shown).

Degradation Behavior of Hydrogels. The degradation of the different photo-cross-linked hydrogels was studied by incubating them at $\mathrm{pH} 7.4$ and $37{ }^{\circ} \mathrm{C}$. Figure $3 \mathrm{~A}$ shows that hydrogels of $20 \mathrm{wt} \%$ degraded in 22, 70, and 110 days, for $\mathrm{M}_{10} \mathrm{P}_{10}, \mathrm{M}_{20} \mathrm{P}_{10}$, and $\mathrm{M}_{30} \mathrm{P}_{10}$, respectively, whereas hydrogels of 35 wt \%, in Figure 3B, exhibited longer degradation times of 37, 225, and 310 days for $\mathrm{M}_{10} \mathrm{P}_{10}, \mathrm{M}_{20} \mathrm{P}_{10}$, and $\mathrm{M}_{30} \mathrm{P}_{10}$, respectively. Similarly, $20 \mathrm{wt} \%$ hydrogels composed of PEGs of different molecular weight degraded in 27 and 70 days for $\mathrm{M}_{20} \mathrm{P}_{20}$ and $\mathrm{M}_{20} \mathrm{P}_{10}$ gel, respectively (Figure $4 \mathrm{~A}$ ), while $35 \mathrm{wt}$ $\%$ hydrogels degraded in 101 and 225 days for $\mathrm{M}_{20} \mathrm{P}_{20}$ and $\mathrm{M}_{20} \mathrm{P}_{10}$, respectively (Figure 4B). The degradation time of both 20 and 35 wt $\% \mathrm{M}_{20} \mathrm{P}_{4}$ hydrogels exceeded 250 days. In agreement with the gel mechanical properties, these results show that the degradation behavior can be fine-tuned by the molecular design of the polymer, in particular, by the extent of methacrylation and by molecular weight of the PEG block. Generally speaking, the higher the $G^{\prime}$ values (and thus the higher the cross- 
A)

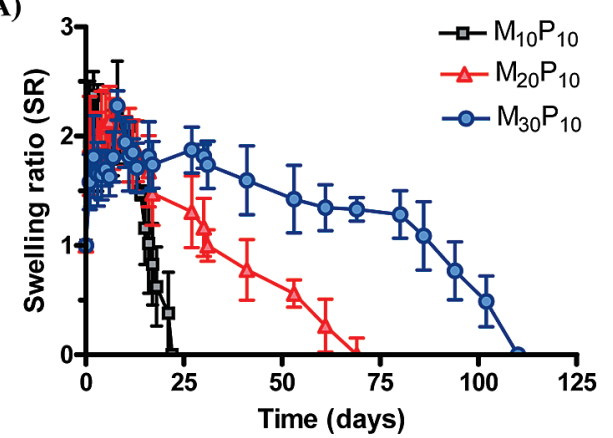

B)

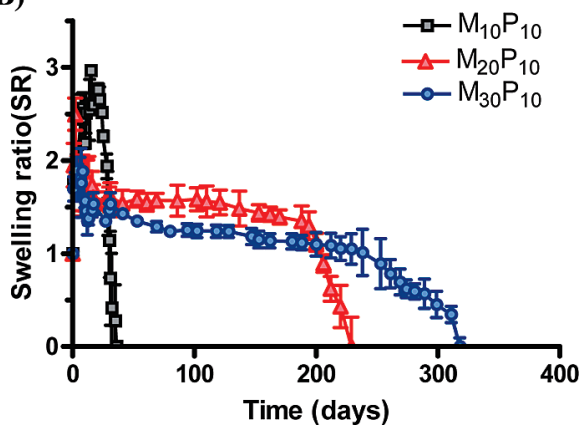

Figure 3. Effect of methacrylation extent on degradation profiles of $M_{10} P_{10}, M_{20} P_{10}$, and $M_{30} P_{10}$ hydrogels (Table 1) during incubation at $37{ }^{\circ} \mathrm{C}$ in PBS buffer $\mathrm{pH} 7.4$, for (A) 20 and (B) 35 wt \% polymer concentration. Data are shown as mean \pm standard deviation; $n=3$.

A)

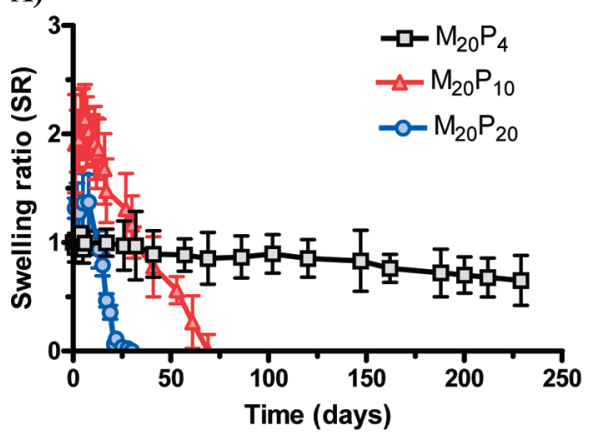

B)

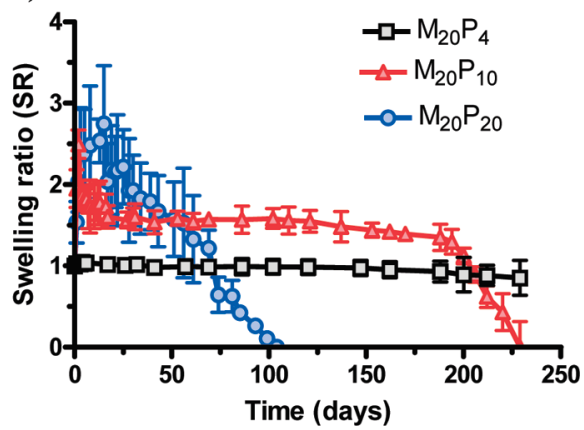

Figure 4. Effect of $P E G$ middle block molecular weight on degradation profiles of $M_{20} P_{4}, M_{20} P_{10}$, and $M_{20} P_{20}$ hydrogels (Table 1) during incubation at $37^{\circ} \mathrm{C}$ in PBS buffer pH 7.4, for (A) 20 and (B) 35 wt \% polymer concentration. Data are shown as mean \pm standard deviation; $n=3$.

A)

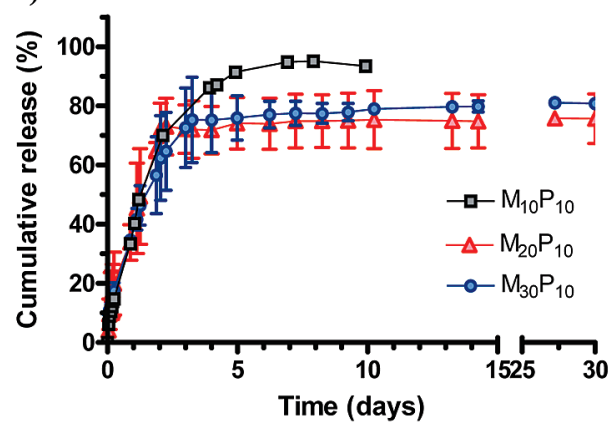

B)

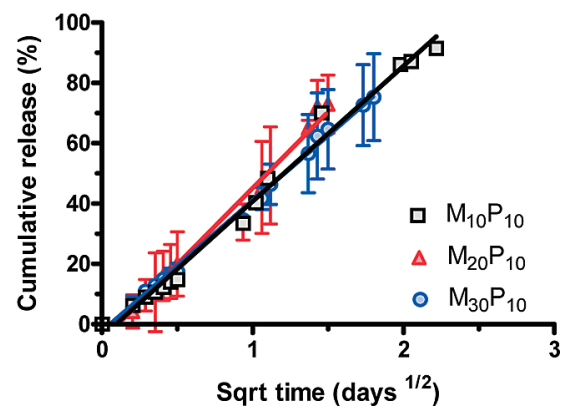

Figure 5. (A) BSA release from $M_{10,20,30} P_{10}$ hydrogels (Table 1) of 20 wt \% polymer concentration. (B) Cumulative release of BSA as a function of the square root of time for $\mathrm{M}_{10,20,30} \mathrm{P}_{10}$ hydrogels of $20 \mathrm{wt} \%$ polymer concentration. Data are shown as mean \pm standard deviation; $n=3$.

link density), the longer the degradation time (compare data of Figures 1 and 2 with Figures 3 and 4). Only the degradation behavior of $\mathrm{M}_{20} \mathrm{P}_{20}$ is not in line with rheological data, because this gel showed the poorest stability despite its high $G^{\prime}$ value compared to the $\mathrm{M}_{20} \mathrm{P}_{10}$ analogues. This observation reinforces the hypothesis that the entanglements of the longer PEG $20 \mathrm{kDa}$ polymer chains are partially responsible for the high $G^{\prime}$ values of the $\mathrm{M}_{20} \mathrm{P}_{20}$ hydrogels, but do not contribute to the long-term stability of the hydrogel.

The degradation mechanism of $\mathrm{p}$ (HPMAm-lac)-PEG-based hydrogels is due to hydrolysis of the numerous ester bonds present in the polymer networks, as described earlier. ${ }^{37,41}$ It was shown that the lactate side chains of p(HPMAm-lac) with a free terminal $\mathrm{OH}$ group are hydrolyzed in approximately 1 week. The terminal lactate moiety in the HPMAm-dilactate is degraded faster than the one in the HPMAm-monolactate, because by a nucleophilic attack of the hydroxy terminus, the ester bond that is located two lactate units further on in the side chain is hydrolyzed in a so-called backbiting mechanism. When these lactate side chains are hydrolyzed, the network becomes more hydrophilic and consequently can absorb more water, resulting in an increasing swelling ratio during the first week, which was indeed observed for almost all degrading hydrogels (Figures 3 and 4). The lactate groups attached to the polymerized methacrylate groups are expected to hydrolyze by random chain scission at a much slower rate due to the lack of a hydroxy terminus. Therefore, a high cross-linking density leads to slow degradation kinetics because of the high number of derivatized hydroxyl groups.

Release Behavior of Hydrogels. The influence of polymer concentration, extent of methacrylation, and molecular weight on BSA release was investigated. In Figure 5, the release profiles of BSA from photopolymerized hydrogels are shown for different methacrylation degrees. Unexpectedly, $\mathrm{M}_{10} \mathrm{P}_{10}, \mathrm{M}_{20} \mathrm{P}_{10}$, and $\mathrm{M}_{30} \mathrm{P}_{10}$ hydrogels of $20 \mathrm{wt} \%$ polymer concentration had the same protein release behavior, being the protein released with the same kinetics in approximately 10 days (Figure 5A). 
A)

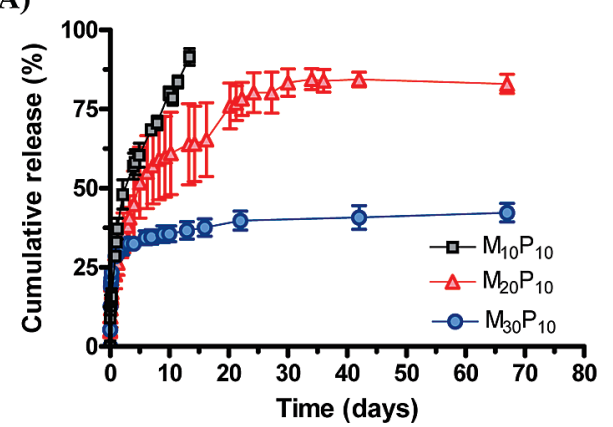

B)

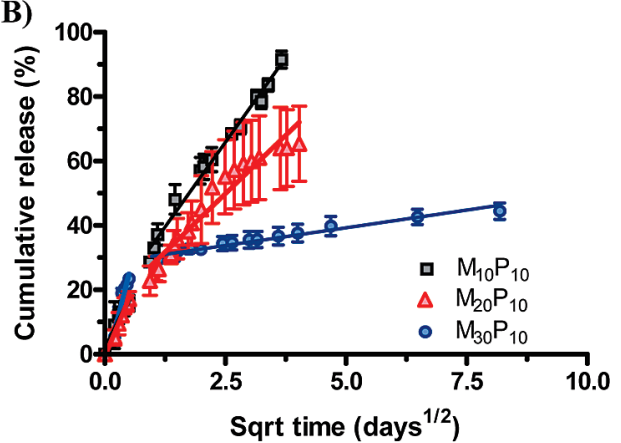

Figure 6. (A) BSA release from $\mathrm{M}_{10,20,30} \mathrm{P}_{10}$ hydrogels (Table 1) of $35 \mathrm{wt} \%$ polymer concentration. (B) Cumulative release of BSA as a function of the square root of time for $\mathrm{M}_{10,20,30} \mathrm{P}_{10}$ hydrogels of $35 \mathrm{wt} \%$ polymer concentration. Data are shown as mean \pm standard deviation; $n=3$.
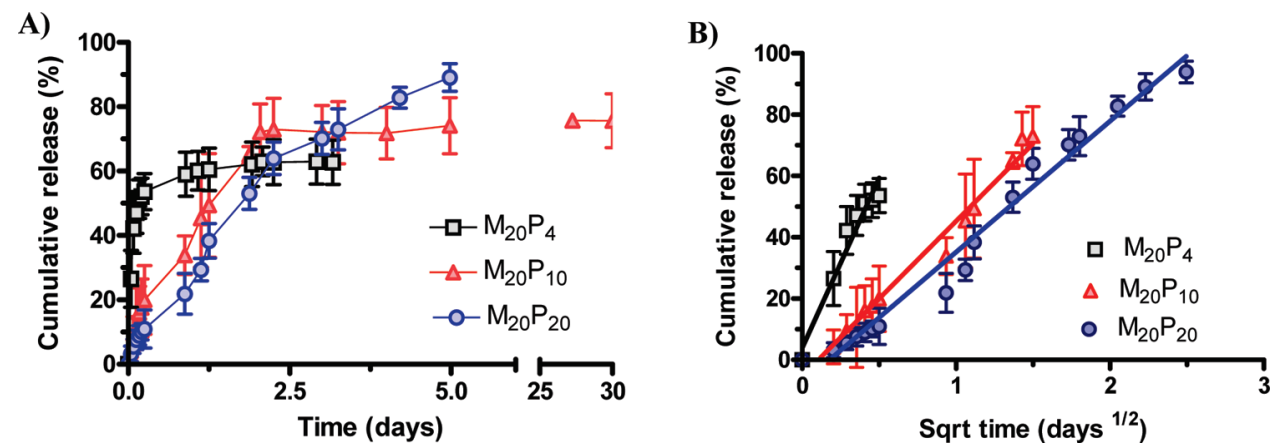

Figure 7. (A) BSA release from $\mathrm{M}_{20} \mathrm{P}_{4,10,20}$ hydrogels (Table 1) of $20 \mathrm{wt} \%$ polymer concentration. (B) Cumulative release of BSA as a function of the square root of time for $\mathrm{M}_{20} \mathrm{P}_{4,10,20}$ polymer hydrogels of 20 wt \% polymer concentration. Data are shown as mean \pm standard deviation; $n=3$.

The release mechanism was investigated by fitting the release curves to the Rigter-Peppas equation: ${ }^{42,43}$

$$
M_{\mathrm{t}} / M_{\infty}=k t^{n}
$$

where $M_{\mathrm{t}} / M_{\infty}$ represents the fractional release of the loaded protein, $k$ is a kinetic constant, $t$ is the release time, and $n$ is the diffusional exponent that can be related to the release mechanism of the entrapped molecules. If $n=0.5$, the release is governed by Fickian diffusion. If $n=1$, molecules are released by surface erosion, while both mechanisms play a role in the release if $n$ has a value between 0.5 and 1 .

The experimental release curves fitted to $n$-values of 0.5 as the data points scaled linearly with the square root of time up to a cumulative release of $80-100 \%$ (Figure 5B), suggesting first order release kinetics. ${ }^{44}$ This fit implies a typical diffusioncontrolled release of the loaded protein with a hydrogel mesh size bigger than the hydrodynamic diameter of the investigated protein. Similar behavior was observed in our previous study, where a diffusion governed release of model proteins of molecular weights ranging between 14 and $150 \mathrm{kDa}$ was found. ${ }^{30}$ From these results it can be concluded that, although the rheological properties and degradation kinetics are dependent on the extent of methacrylation, the release kinetics are hardly affected by this parameter. At low polymer concentration, the density of hydrophobic domains is low and the protein likely resides preferentially in the hydrophilic areas of the hydrogels. The increase in the extent of methacrylation affects the crosslink density within the hydrophobic domains but does not influence the hydrophilic compartments.

The release of BSA from $\mathrm{M}_{10,20,30} \mathrm{P}_{10}$ hydrogels of $35 \mathrm{wt} \%$ polymer concentration is shown in Figure 6. A biphasic release kinetics comprising an initial fast release during approximately 5 days, followed by a slower release phase highly influenced by the cross-link density, was observed. When the polymer concentration of $\mathrm{M}_{10,20,30} \mathrm{P}_{10}$ hydrogels increases from 20 to 35 wt $\%$, the volume fraction of the hydrophobic domains also increases, and the protein partitions both in the hydrophilic and in the hydrophobic areas of the hydrogels. The rapid release during the initial stage is most likely caused by protein that is released from the hydrophilic domains in the gels. As pointed out above, this release is not affected by the extent of methacrylation. The second phase of release can then be attributed to protein encapsulated in the hydrophobic domains of the gels. However, because the chemical cross-links are present in the hydrophobic domains, the release of BSA encapsulated in these compartments is dependent on the DM. In particular, the mobility of the protein is more restricted in hydrogels of higher methacrylation degree.

Hydrogels of different PEG molecular weights showed similar BSA release behavior for 20 and $35 \mathrm{wt} \%$ polymer concentration (Figures 7 and 8). However, in contrast to the results of rheological and degradation studies, the hydrogels of longer PEG chains, $\mathrm{M}_{20} \mathrm{P}_{20}$, displayed relatively slow BSA release kinetics in 5 and 67 days, for 20 and $35 \mathrm{wt} \%$ polymer concentration, respectively. Surprisingly, the $\mathrm{M}_{20} \mathrm{P}_{4}$ hydrogels, instead, exhibited very fast release in 2.5 and 4 days for 20 and 35 wt \% polymer concentrations, respectively (discussed further in the next section). A small burst release (approximately 4 and 2\% for 20 and $35 \mathrm{wt} \%$ polymer hydrogels) was also observed in the release kinetics of $\mathrm{M}_{20} \mathrm{P}_{4}$ hydrogels, likely attributable to the slight shrinkage of hydrogel and the expulsion of protein upon gel formation. Diffusion controlled $(n=0.5)$ monophasic release was shown for 20 wt $\% \mathrm{M}_{20} \mathrm{P}_{4}, \mathrm{M}_{20} \mathrm{P}_{10}$, and $\mathrm{M}_{20} \mathrm{P}_{20}$ hydrogels as well as for $35 \mathrm{wt} \% \mathrm{M}_{20} \mathrm{P}_{20}$ hydrogels, where the 
A)

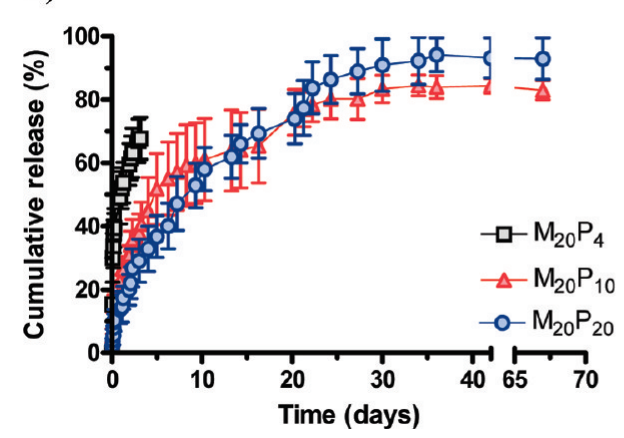

B)

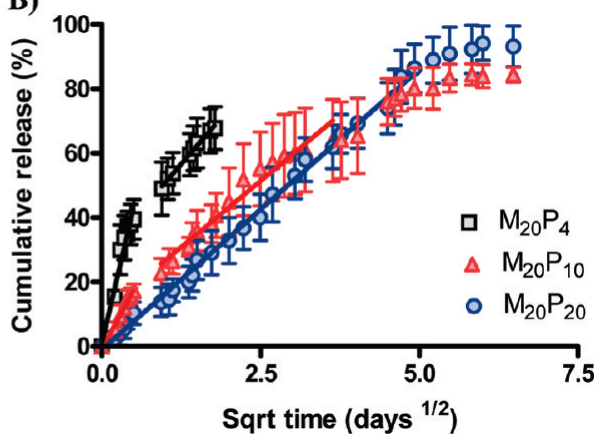

Figure 8. (A) BSA release from $\mathrm{M}_{20} \mathrm{P}_{4,10,20}$ hydrogels (Table 1) of $35 \mathrm{wt} \%$ polymer concentration. (B) Cumulative release of BSA as a function of the square root of time for $\mathrm{M}_{20} \mathrm{P}_{4,10,20}$ polymer hydrogels of $35 \mathrm{wt} \%$ polymer concentration. Data are shown as mean \pm standard deviation; $n=3$.

hydrophilicity is most predominant. $\mathrm{M}_{20} \mathrm{P}_{4}$ and $\mathrm{M}_{20} \mathrm{P}_{10}$ hydrogels at $35 \mathrm{wt} \%$ polymer concentration, with higher hydrophobicity, displayed biphasic release (Figure 8A,B).

Most of the studied hydrogels (20 wt $\% \mathrm{M}_{10,20,30} \mathrm{P}_{10}, 35 \mathrm{wt}$ $\% \mathrm{M}_{10,20} \mathrm{P}_{10}, 20$ and $35 \mathrm{wt} \% \mathrm{M}_{20} \mathrm{P}_{20}$ ) showed quantitative release within the experimental error (cumulative release higher than $80 \%$ ), however, some formulations (35 wt $\% \mathrm{M}_{30} \mathrm{P}_{10}, 20$ and 35 wt $\% \mathrm{M}_{20} \mathrm{P}_{4,20}$ ), having relatively high hydrophobic domain volume fractions, exhibited incomplete BSA release during the studied time scale. This observation leads to the conclusion that when the protein is located mainly in the hydrophilic PEG domains or in hydrophobic domains of relatively low crosslink density, the protein is totally released by diffusion and the degradation of the matrix is not an important factor, whereas when the protein resides in highly cross-linked hydrophobic domains, its mobility is remarkably restricted and degradation of the hydrogel is needed for the complete release thereof. These findings were supported by fluorescence recovery after photobleaching (FRAP) experiments ${ }^{45}$ (Supporting Information), where decreasing mobile fractions were found with increasing cross-link densities. Also, the protein diffusional behavior in polymer networks of both different methacrylate extent and PEG length was studied by FRAP analysis and compared to the release kinetics. Good agreement between FRAP and release data was found as the diffusion coefficients of fluorescently labeled BSA followed the same trends both in FRAP and in release experiments (Supporting Information).

The tailorability of protein release from chemically crosslinked thermosensitive hydrogels was studied also by Wang et al. ${ }^{46}$ Similar to $\mathrm{M}_{20} \mathrm{P}_{10}$ and $\mathrm{M}_{20} \mathrm{P}_{20}$ hydrogels of $35 \mathrm{wt} \%$ solid content, a quantitative BSA release of 35 days from Pluronic F127-poly(caprolactone) copolymer-based hydrogels was found and the in vitro release rate was negatively correlated to the molecular weight of proteins, as we also reported previously for photo-cross-linked p(HPMAm-lac)-PEG-p(HPMAm-lac) hydrogels. ${ }^{30}$ However, in contrast to our studies, where the release mechanism was diffusional, Wang et al. demonstrated that both diffusion and degradation of the matrix contributed to the protein release. Other UV-cured (thermosensitive) hydrogels showed faster release kinetics. Photopolymerized hyaluronic acid/ Pluronic hydrogels were used by Kim and Park to investigate the release of human growth hormone. ${ }^{47} \mathrm{~A}$ release time span of 13 days was found at $37{ }^{\circ} \mathrm{C}$ and the mechanism was governed by erosion. BSA was released in 5 days from photopolymerized degradable PEG hydrogels based on diacrylated oligo-lactide derivatized PEG, ${ }^{32}$ and the release depended on both permeability of the matrix prior to degradation and its degradation rate.

Leach et al. ${ }^{48}$ developed highly diffusive photo-cross-linkable hyaluronic acid-polyethylene glycol hydrogels that showed a decrease of BSA diffusion coefficient $(D)$ with increasing concentration of hydrogel precursors, as is also found in the present study (Supporting Information) as well as in other studies. ${ }^{49}$ Moreover, in line with our release kinetics from the hydrophilic gel compartments, where diffusion coefficients of BSA varying from 1.1 to $52.9 \mu \mathrm{m}^{2} / \mathrm{sec}$ were found (Figures 3SI-A and 4SI-A, Supporting Information), a range of $D$ s from 8.5 to $45.4 \mu \mathrm{m}^{2} / \mathrm{sec}$ were obtained for hyaluronic acid/Pluronic hydrogels. $^{48}$

The diffusion coefficients based on release experiments from the highly cross-linked hydrophobic domains, ranging between 0.01 and $3.5 \mu \mathrm{m}^{2} / \mathrm{sec}$ (Figures 3SI-B and 4SI-B, Supporting Information), were comparable to the ones published for photocross-linked low molecular weight PEG hydrogels. ${ }^{50,51}$ As expected, it appears that the high cross-linking density, due to the short PEG chains of the hydrogels described by Mellott et al. ${ }^{50}$ and Cruise et al. ${ }^{51}$ or to the high methacrylation extent of our hydrophobic domains, results in low protein diffusivity.

Highly cross-linked gel networks are ideal as controlled release systems for proteins, as they allow their delivery over a prolonged time scale. However, the use of photo-cross-linked PEG hydrogels is limited by their lack of biodegradability; therefore, the system we describe in the present paper, showing slowly diffusive release phases, represents an advantage over existing hydrogel systems.

Confocal Laser Scanning Microscopy. To gain more insight into the hydrogel microstructure, confocal laser scanning microscopy (CLSM) was performed on $\mathrm{M}_{20} \mathrm{P}_{4,10,20,40}$ hydrogels, in which the hydrophobic domains were stained with the hydrophobic dye NR and the hydrophilic pores with FITC-BSA. $\mathrm{M}_{20} \mathrm{P}_{40}$ was used only in CLSM studies because its high viscosity even below the CP, due to entanglement of the PEG chains, makes the injectability of the hydrogel difficult, thus, practical application of this gel system is limited. However, this polymer is a valuable tool to investigate the hydrogel structural organization at different molecular designs. From Figure 9, an evident hydrogel microporosity dependency on PEG molecular weight can be seen, as previously also observed in our studies on p(HPMAm-lac)-PEG-p(HPMAm-lac) physical hydrogels. ${ }^{40} \mathrm{~A}$ similar behavior was observed for hydrogels of $20 \mathrm{wt} \%$ polymer concentration (data not shown). This remarkable porosity of hydrogels of small PEG molecular weight is likely due to a phase separation with hydrophilic domains surrounded by a polymer-rich phase. The extent of phase separation within the hydrogel is strongly related to the hydrophilicity-hydrophobicity balance between PEG and p(HPMAm-lac). The observed phase separation explains the BSA release behavior of the studied hydrogels. BSA, localized in the water-rich phase separated domains, is expected to be minimally restricted in mobility and 

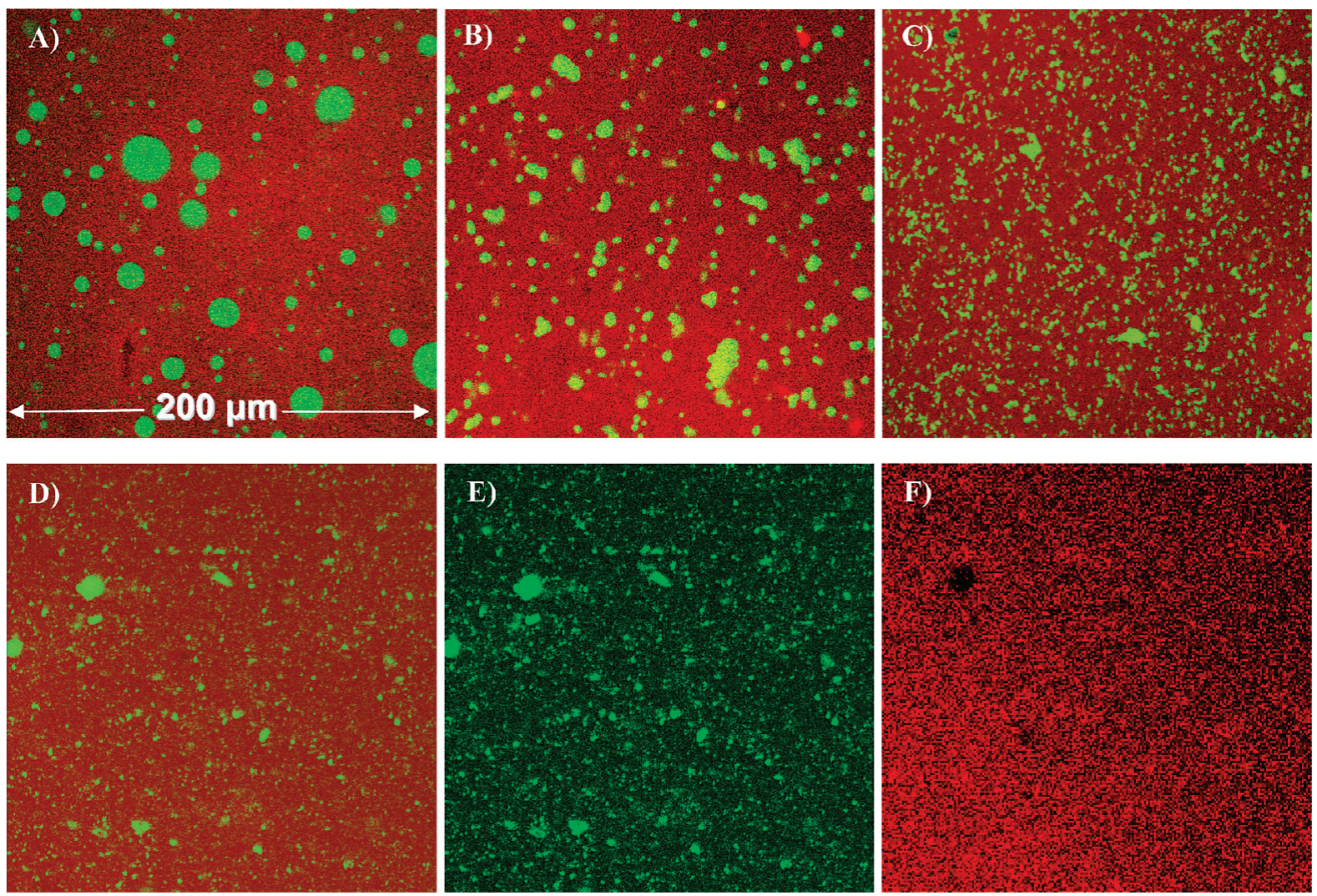

Figure 9. Confocal laser scanning microscopy pictures of $\mathrm{M}_{20} \mathrm{P}_{4,10,20}$ hydrogels (Table 1) double stained with hydrophobic NR (in red) and hydrophilic fluorescein isothiocyanate FITC-BSA (in green): (A) 35 wt \% $\mathrm{M}_{20} \mathrm{P}_{4}$ polymer hydrogels based on PEG $4 \mathrm{kDa}$; (B) 35 wt \% $\mathrm{M}_{20} \mathrm{P}_{10}$ polymer hydrogels based on PEG $10 \mathrm{kDa}$; (C) $35 \mathrm{wt} \% \mathrm{M}_{20} \mathrm{P}_{20}$ polymer hydrogels based on PEG $20 \mathrm{kDa}$; (D-F) $35 \mathrm{wt} \% \mathrm{M}_{20} \mathrm{P}_{40}$ polymer hydrogels based on PEG $40 \mathrm{kDa}$; pictures show the FITC-BSA/NR double staining (D) as well as the FITC-BSA staining (E) and NR staining (F).

thereby rapidly released. Likely, the micropores are interconnected by smaller hydrophilic nanopores, which are hardly visible on CLSM pictures, but their presence is proven by the colocalization of FITC-BSA (Figure 9E) and NR (Figure 9F) in the polymer-rich phase, shown for $\mathrm{M}_{20} \mathrm{P}_{40}$ hydrogels. In the superimposed picture (Figure 9D) where the double staining is shown, the presence of FITC-BSA in the nanopores of the polymer-rich phase is poorly visible due to the higher signal given by NR as compared to FITC-BSA.

On the other hand, the mobility of the BSA encapsulated in the hydrophilic domains of the hydrogel networks where the microphase separation is minimal or indiscernible, like in case of $\mathrm{M}_{20} \mathrm{P}_{20}$ and even more markedly of $\mathrm{M}_{20} \mathrm{P}_{40}$ hydrogels, is much more limited. In fact, prior to release, the protein has to diffuse through smaller hydrophilic domains, as compared to more phase-separated hydrogels. Finally, the protein possibly entrapped in the hydrophobic domains is immobile or slowly diffusing due to the presence of chemical cross-links that represent barriers to the macromolecular diffusion.

The demonstrated polymer phase separation lends itself to explain also the mechanical properties of the hydrogels. Likely, the phase separation induces the formation of domains with high polymer concentration that highly contribute to the gel strength. The hydrophilic-hydrophobic balance plays a key role in the structural organization of the hydrogel, leading to phase separation and to the tendency to expel water if the hydrophobic character of the hydrogels is dominant.

\section{Conclusions}

In this paper, we described how the molecular design of a thermosensitive methacrylate bearing A-B-A triblock copolymer tailored the mechanical properties, degradation, and protein release behavior of hydrogels prepared using these polymers. Increasing the degree of methacrylation and decreasing the PEG molecular weight led to a higher cross-link density and to the formation of hydrogels of increased storage modulus and enhanced stability to the hydrolytic degradation at physiological $\mathrm{pH}$. BSA was released from hydrogels by a mechanism mainly governed by diffusion. Nevertheless, the cross-link density not always correlated to the BSA release rate, which was independent of the extent of methacrylation for $20 \mathrm{wt} \%$ hydrogels and for the initial phase of the biphasic release of $35 \mathrm{wt} \%$ polymer gels. The extent of methacrylation affected the cross-link density within the hydrophobic domains, and only the release rate of BSA that resides partly in those self-assembled domains can be tailored by the cross-link density. On the other hand, hydrogels of longer PEG polymer chain exhibited an unexpected slower release rate. CLSM analysis clarified that the gels were phase-separated into water-rich hydrophilic and polymer-rich hydrophobic domains and that the extent of phase separation could be controlled by the PEG block length of the polymer. Hydrogels of small PEG blocks showed large hydrophilic domains from which the protein was rapidly released. Hydrogels of longer PEG blocks showed a more homogeneous structure resulting in slower protein diffusion.

In conclusion, the studied hydrogels are excellent candidates as injectable biomaterials for the controlled delivery of biotherapeutics because their versatility and flexibility allow precise tailoring of mechanical properties, degradation profiles, and release behavior to the desired pharmacokinetics of each specific drug. 
Acknowledgment. This research was supported by the Dutch Program for Tissue Engineering (DPTE; Project Number 6731). Confocal images were acquired at the Center for Cellular Imaging (CCI) in the Faculty of Veterinary Medicine, and we thank E.M. van't Veld and Dr. R. Wubbolts for help and technical advice.

Supporting Information Available. Additional materials and methods information and analytical details. This material is available free of charge via the Internet at http://pubs.acs.org.

\section{References and Notes}

(1) Blanchard, J. J. Am. Chem. Soc. 1998, 120, 4554-4555.

(2) Deo, S. K.; Moschou, E. A.; Peteu, S. F.; Bachas, L. G.; Daunert, S.; Eisenhardt, P. E.; Madou, M. J. Anal. Chem. 2003, 75, 206 A213 A.

(3) D'Emanuele, A. Clin. Pharmacokinet. 1996, 31, 241-245.

(4) Bruguerolle, B. Clin. Pharmacokinet. 1998, 35, 83-94.

(5) Gupta, P.; Vermani, K.; Garg, S. Drug Discovery Today 2002, 7, 569579.

(6) Peppas, N. A.; Bures, P.; Leobandung, W.; Ichikawa, H. Eur. J. Pharm. Biopharm. 2000, 50, 27-46.

(7) Minh Khanh, N.; Doo Sung, L. Macromol. Biosci., doi: 0.1002/ mabi.200900402 NA.

(8) Frokjaer, S.; Otzen, D. E. Nat. Rev. Drug Discovery 2005, 4, 298306.

(9) van de Weert, M.; Hennink, W. E.; Jiskoot, W. Pharm. Res. 2000, $17,1159-1167$

(10) Jiskoot, W.; van Schie, R.; Carstens, M.; Schellekens, H. Pharm. Res. 2009, 26, 1303-1314.

(11) Iza, M.; Stoianovici, G.; Viora, L.; Grossiord, J. L.; Couarraze, G. J. Controlled Release 1998, 52, 41-51.

(12) van de Wetering, P.; Metters, A. T.; Schoenmakers, R. G.; Hubbell, J. A. J. Controlled Release 2005, 102, 619-627.

(13) Bourke, S.; Al-Khalili, M.; Briggs, T.; Michniak, B.; Kohn, J.; PooleWarren, L. AAPS J. 2003, 5, 101-111.

(14) Mason, M. N.; Metters, A. T.; Bowman, C. N.; Anseth, K. S. Macromolecules 2001, 34, 4630-4635.

(15) Siepmann, J.; Peppas, N. A. Pharm. Res. 2000, 17, 1290-1298.

(16) Anderson, D. G.; Tweedie, C. A.; Hossain, N.; Navarro, S. M.; Brey, D. M.; Van Vliet, K. J.; Langer, R.; Burdick, J. A. Adv. Mater. 2006, $18,2614-2618$.

(17) Nathanael, R. L.; Kimberly, A. S.; Mark, W. G. Chem.-Eur. J. 2003, 9, 5618-5626.

(18) Hennink, W. E.; Cadée, J. A.; Jong, S. J.; Franssen, O.; Stenekes, R. J. H.; Talsma, H.; Dijk-Wolthuis, W. N. E. In Biomedical Polymers and Polymer Therapeutics; Springer: New York, 2002; pp 3-18.

(19) Jeong, B.; Gutowska, A. Trends Biotechnol. 2002, 20, 305-311.

(20) Klouda, L.; Mikos, A. G. Eur. J. Pharm. Biopharm. 2008, 68, 34-45.

(21) Soga, O.; van Nostrum, C. F.; Hennink, W. E. Biomacromolecules 2004, 5, 818-821.

(22) Vermonden, T.; Besseling, N. A. M.; van Steenbergen, M. J.; Hennink, W. E. Langmuir 2006, 22, 10180-10184.

(23) Zhang, H.-f.; Zhong, H.; Zhang, L.-1.; Chen, S.-b.; Zhao, Y.-j.; Zhu, Y.-L.; Wang, J.-t. Carbohydr. Polym. , 79, 131-136.
(24) Kretlow, J. D.; Klouda, L.; Mikos, A. G. Adv. Drug Delivery Rev. 2007, 59, 263-273.

(25) Van Tomme, S. R.; Storm, G.; Hennink, W. E. Int. J. Pharm. 2008, $355,1-18$.

(26) Hennink, W. E.; van Nostrum, C. F. Adv. Drug Delivery Rev. 2002, 54, 13-36.

(27) Paradossi, G.; Finelli, I.; Cerroni, B.; Chiessi, E. Molecules 2009, 14, 3662-3675.

(28) Machado, L.; Bavaresco, V.; Pino, E.; Zavaglia, C.; Reis, M. J. Therm. Anal. Calorim. 2004, 75, 445-451.

(29) Vanderhooft, J. L.; Alcoutlabi, M.; Magda, J. J.; Prestwich, G. D. Macromol. Biosci. 2009, 9, 20-28.

(30) Censi, R.; Vermonden, T.; van Steenbergen, M. J.; Deschout, H.; Braeckmans, K.; De Smedt, S. C.; van Nostrum, C. F.; di Martino, P.; Hennink, W. E. J. Controlled Release 2009, 140, 230-236.

(31) Vermonden, T.; Fedorovich, N. E.; van Geemen, D.; Alblas, J.; van Nostrum, C. F.; Dhert, W. J. A.; Hennink, W. E. Biomacromolecules 2008, 9, 919-926.

(32) West, J. L.; Hubbell, J. A. React. Polym. 1995, 25, 139-147.

(33) Nguyen, K. T.; West, J. L. Biomaterials 2002, 23, 4307-4314.

(34) Lu, S.; Anseth, K. S. J. Controlled Release 1999, 57, 291-300.

(35) Elisseeff, J.; Anseth, K.; Sims, D.; McIntosh, W.; Randolph, M.; Langer, R. Proc. Natl. Acad. Sci. U.S.A. 1999, 96, 3104-3107.

(36) Bryant, S. J.; Nuttelman, C. R.; Anseth, K. S. J. Biomater. Sci., Polym. Ed. 2000, 11, 439-457.

(37) Neradovic, D.; van Steenbergen, M. J.; Vansteelant, L.; Meijer, Y. J.; van Nostrum, C. F.; Hennink, W. E. Macromolecules 2003, 36, 74917498.

(38) Alakhov, V. Y.; Kabanov, A. V. Expert Opin. Invest. Drugs 2005, 7 , $1453-1473$

(39) Soga, O.; van Nostrum, C. F.; Ramzi, A.; Visser, T.; Soulimani, F.; Frederik, P. M.; Bomans, P. H. H.; Hennink, W. E. Langmuir 2004, 20, 9388-9395.

(40) Vermonden, T.; Jena, S. S.; Barriet, D.; Censi, R.; van der Gucht, J.; Hennink, W. E.; Siegel, R. A. Macromolecules 2009, 43, 782-789.

(41) Rijcken, C. J.; Snel, C. J.; Schiffelers, R. M.; van Nostrum, C. F.; Hennink, W. E. Biomaterials 2007, 28, 5581-5593.

(42) Ritger, P. L.; Peppas, N. A. J. Controlled Release 1987, 5, 37-42.

(43) Serra, L.; Doménech, J.; Peppas, N. A. Biomaterials 2006, 27, 54405451.

(44) Schwartz, J. B.; Simonelli, A. P.; Higuchi, W. I. J. Pharm. Sci. 1968, 57, 274-277.

(45) Brandl, F.; Kastner, F.; Gschwind, R. M.; Blunk, T.; Te $\beta$ mar, J.; Göpferich, A. J. Controlled Release 2010, 142, 221-228.

(46) Wang, B.; Zhu, W.; Zhang, Y.; Yang, Z.; Ding, J. React. Funct. Polym. 2006, 66, 509-518.

(47) Kim, M. R.; Park, T. G. J. Controlled Release 2002, 80, 69-77.

(48) Leach, J. B.; Schmidt, C. E. Biomaterials 2005, 26, 125-135.

(49) Amsden, B. Macromolecules 1998, 31, 8382-8395.

(50) Mellott, M. B.; Searcy, K.; Pishko, M. V. Biomaterials 2001, 22, 929 941.

(51) Cruise, G. M.; Scharp, D. S.; Hubbell, J. A. Biomaterials 1998, 19, 1287-1294.

BM100514P 